\title{
PENERAPAN KESELAMATAN DAN KESEHATAN KERJA PADA CV. CIPTA MANDIRI DI KABUPATEN KENDAL
}

\author{
Muhammad Nanang Setiawan, Widodo Hariyono, Surahma Asti Mulasari \\ Fakultas Kesehatan Masyarakat, Universitas Ahmad Dahlan, Yogyakarta
}

\begin{abstract}
Background: the realization management health and occupational very important to a company. In the CV Cipta Mandiri still occured job accident that can damage employee although facilities that available. As long as CV Cipta Mandiri has perform management system safety and health occupational until necessary does evaluation of realization system.

Method: this research constitute of descriptive research with planning cross sectional. The collect of data with does analysis direct on field and interview going deep to researce person.

Result : the facilities of work is good, but it need completed wirh maintanance for good function. The company have comitment for does management system safety and job safety program for prevent occupational accident, such as training and counseling. Generally, realization of apply safety and system can run well.

Conclusion: the management system of safety and healthy job includes having good facilities. Comitment of the company and the program of preventing accident in a job has been run well, but there must be luck in other aspect that must be improved.
\end{abstract}

Keywords: health, occupational, safety, implementation

\section{PENDAHULUAN}

Dewasa ini dunia industri di Indonesia berkembang sangat pesat, seiring dengan kemajuan ilmu pengetahuan dan teknologi. Pemanfaatan teknologi di dalam dunia industri juga sangat bervariasi, dari teknologi yang sederhana sampai dengan teknologi yang kompleks. Kompleksnya peralatan yang digunakan, makin besar pula potensi bahaya yang mungkin akan terjadi dan makin besar pula kecelakaan kerja yang ditimbulkan apabila tidak dilakukan penanganan yang benar dan sebaik mungkin.

Era globalisasi saat ini, tuntutan masyarakat akan upaya perlindungan tenaga kerja makin kuat. Masyarakat pun menghendaki agar tenaga kerja selalu dalam keadaan selamat dan sehat yang secara tidak langsung juga berpengaruh, sehingga penerapan K3 dan Keselamatan Kerja harus dilaksanakan sebagai bagian dari pelaksanaan hak asasi manusia.

Undang-Undang Kesehatan dan Keselamatan Kerja menyatakan bahwa telah memberikan tanggung jawab kepada manajemen untuk melaksanakan pencegahan Kecelakaan Kerja. Walaupun banyak perusahaan yang belum begitu mengetahui tentang potensi-potensi bahaya di tempat kerja yang terkait dengan peraturan perundangan tentang Keselamatan Kerja, sehingga masih banyak pelanggaran dan perlu pengawasan agar terhindar dari kecelakaan dan penyakit akibat kerja. ${ }^{1}$

Adanya kecelakaan merupakan masalah yang sangat penting karena sangat merugikan pekerja dan perusahaan. Pekerja dirugikan sebab mereka mengalami kesakitan, kecacatan bahkan bisa berakibat kematian, sedangkan perusahaan juga dirugikan karena adanya kecelakaan kerja yang berarti adanya asset yang berupa sumber daya, bagian mesin,bahan, peralatan atau lingkungan kerja yang 
rusak. Maka akibat dari itu, bisa menyebabkan kekacauan di dalam proses produksi.

Kerugian yang disebabkan oleh kecelakaan tersebut sangatlah besar dan biasa memungkinkan semua pihak yang terlibat baik pekerja maupun pimpinan perusahaan dan selaku penentu kebijakan harus memahami dan menerapkan program-program tentang Keselamatan dan Kesehatan Kerja (K3) sehingga tercipta lingkungan kerja yang aman, nyaman dan sehat pula. Maka dengan demikian jumlah kecelakaan kerja dapat ditekan dan perusahaan tidak akan mengalami suatu kerugian. Maka perlu dilakukan dengan menganalisis kecelakaan kerja sehingga dapat mengurangi atau mencegah adanya kecelakaan kerja.

Notoatmodjo $^{2}$ mengungkapkan bahwa menganalisis suatu kecelakaan kerja merupakan salah satu tujuan untuk menentukan faktor-faktor kecelakaan kerja dengan kecelakaan yang telah terjadi. Cara analisis ini data dilakukan dengan mengadakan penyelidikan atau pemeriksaan terhadap peristiwa kecelakaan tersebut. Obyek analisis kecelakaan kerja tidak hanya terbatas pada unsur manusia dan lingkungan saja, tetapi juga menelusuri adanya penyebab pendorong yang lain. ${ }^{3}$

Analisis kecelakaan kerja merupakan salah satu bagian dari pelaksanaan program keselamatan dan kesehatan kerja. Oleh karena itu, perusahaan harus menerapkan untuk mencegah terjadinya suatu kerugian yang tidak diinginkan. Setiap perusahaan yang menggunakan peralatan dalam proses produksi dan menjadikan manusia sebagai operatornya, maka dapat dipastikan bahwa di tempat itu terdapat suatu potensi terjadi kecelakaan. Seperti halnya dengan CV. Cipta Mandiri yang berada di daerah Paturen Pagersari Kecamatan Patean Kabupaten Kendal merupakan salah satu Perusahaan industri kayu lapis yang bergerak di bidang pembuatan triplek, yang didalam proses produksinya dengan menggunakan peralatan misalkan mesin produksi, alat potong, tempat open bahan mentah triplek, tungku pembakaran yang beragam yang dioperasionalkan oleh para pekerja industri, sehingga kemunculan terjadinya suatu kecelakaan kerja tersebut sangatlah besar. Hal tersebut dapat mengganggu efisiensi, produktivitas, keselamatan dan kesehatan kerja. Meskipun dengan demikian, angka kecelakaan kerja di CV. Cipta Mandiri relatif kecil, bahkan menurut hasil wawancara dengan kepala sub bagian administrasi pada tanggal 17 November 2008 menerangkan bahwa tiap tahun kecelakaan kerja yang terjadi relatif kecil.

Walaupun faktor kecelakaan kerja sangatlah kecil, tetap perlu dilakukan upaya perbaikan dan penanganan lebih lanjut, hal ini terlihat perusahaan hanya melakukan pemantauan-pemantauan secara personal dan kurangnya upaya perbaikan lebih lanjut, untuk itu komitmen dan kebijakan manajemen perusahaan dan keterlibatan pekerja dalam menciptakan budaya K3 perlu dioptimalkan untuk menciptakan kondisi lingkungan kerja aman, sehat dan nyaman terhindar dari kecelakaan kerja (Bagian SDM dan CV. Cipta Mandiri, 2008). Berdasarkan uraian di atas, penulis melakukan penelitian terhadap penerapan keselamatan kerja dan kesehatan kerja yang dilakukan di CV. Cipta Mandiri, sehingga perusahaan tersebut dapat sebagai contoh bagi perusahaan lain tentang keselamatan dan kesehatan kerja.

\section{METODE PENELITIAN}

Jenis penelitian ini adalah penelitian kualitatif dengan rancangan deskriptif observasional yang berupaya melakukan analisis tentang penerapan Keselamatan Dan Kesehatan Kerja (K3) di CV. Cipta Mandiri Paturen Pagersari yang meliputi ketersediaan sarana dan prasarana, komitmen perusahaan, dan pelaksanaan pencegahan dalam menunjang program keselamatan dan kesehatan kerja (K3) di tempat kerja. 
Waktu dalam observasi dari bulan April sampai Juni 2010. Lokasi penelitian ini yaitu di CV. Cipta Mandiri Paturen Pagersan Kecamatan Patean, Kabupaten Kendal-Jateng, dan penelitian ini dilakukan di semua ruangan unit kerja di CV. Cipta Mandiri.

Subyek penelitian adalah melibatkan kepala unit kerja P2K3 CV Cipta Mandiri (responden A), 1 anggota unit kerja P2K3 (responden B), dan 1 orang karyawan (responden C). Untuk memperoleh keterangan secara rinci, jelas, lengkap dan mendalam maka dilakukan wawancara secara terstruktur dan analisa data kecelakaan kerja dan program-program K3.

\section{HASIL PENELITIAN DAN PEMBAHASAN}

\section{a. Hasil Penelitian}

\section{1) Sarana dan Prasarana}

a) Sarana Alat Pelindung Diri

Terjadinya kecelakaan kerja disebabkan oleh beberapa faktor diantaranya faktor fisik dan manusia. Kondisi lingkungan yang tidak aman seperti lantai licin, pencahayaan kurang, mesin yang terbuka juga bisa menjadi penyebab timbulnya kecelakaan kerja. Di perlukan sarana dan pra sarana untuk menghindarkan diri dari kecelakaan pada saat bekerja. Adanya sarana maupun prasarana yang baik untuk bekerja dapat mencegah terjadinya gangguan kesehatan dalam bekerja. Di samping itu juga dapat memberikan perlindungan bagi pekerja didalam melakukan pekerjaannya.

Tabel 2. Daftar Sarana dan Prasarana Keselamatan dan Kesehatan

Kerja CV Cipta Mandiri Tahun 2010

\begin{tabular}{clc}
\hline No & \multicolumn{1}{c}{ Nama barang } & Jumlah \\
\hline 1 & Peralatan P3K & 1 buah \\
\hline 2 & Alat pemadam kebakaran & 4 buah \\
\hline 3 & Helm & 20 buah \\
\hline 4 & Sarung tangan & 200 buah \\
\hline 5 & Sepatu but & 20 buah \\
\hline 6 & Baju werpak & 3 buah \\
\hline 7 & masker & 22 buah \\
\hline
\end{tabular}

Sarana seperti alat pelindung diri atau APD harus selalu tersedia untuk melindungi diri para pekerja dari kecelakaan. CV Cipta Mandiri selama ini sudah memiliki beberapa alat pelindung diri untuk para pekerjanya. Peryantaan ini diungkapkan oleh kepala kantor sebagai berikut :

"Pencegahannya lewat penyuluhan,pelatihan dan pengarahan sebelum bekerja selain itu juga ada sarana untuk pelindung diri maupun perlengkapan lain." (Responden A) 
Hasil wawancara yang sama juga diungkapkan oleh beberapa karyawan bahwa di perusahaan ini terdapat alat pelindung diri, berikut hasil wawancara :

"Sarananya ada seperti helm." (Responden B)

"...memakai alat pelindung mas seperti helm,sepatu bot." (Responden C)

Selain alat pelindung diri juga tersedia sarana lain untuk mencegah terjadinya kecelakaan kerja seperti alat pemadam kebakaran. Hal ini disampaikan oleh beberapa responden dalam wawancara sebagai berikut :

"Untuk alat pemadam kebakaran sudah ada lengkap, hanya saja

jumlahnya belum banyak." (Responden A)

"Sudah ada alat pemadam kebakaran" (Responden B)

"ya, ada alat pemadam kebakaran berjumlah 4. Diletakkan setiap 20 meter. "(Responden C)

Alat pelindung diri dapat digunakan sebagai pengaman utama, tetapi juga perlu ada pra sarana seperti poster agar karyawan selalu ingat bahwa penting untuk menggunakan alat pelindung diri. Sedangkan di CV Cipta Mandiri saat ini belum ada poster tentang APD tersebut. Hal ini disampaikan oleh salah satu responden sebagai berikut :

"Belum ada posternya..." (Responden C)

Saat ini di perusahaan tersebut belum pernah terjadi kecelakaan yang besar dan hanya terjadi kecelakaan kecil sperti terjatuh, dan kebakaran kecil. Hal ini disampaikan oleh beberapa responden dalam wawancara berikut :

"Kalau kecelakaan besar belum ada, cuma kecelakaan kecil seperti terpeleset atau jatuh tapi untuk kebakaran besar belum pernah ada." (Responden C)

"Selama ini belum pernah terjadi, tapi untk kecelakaan kecil sudah pernah." (Responden A)"

"Belum pernah ada mas, paling jatuh atau kepeleset atau kebakaran kecil." (Responden B)"

Belum pernah adanya kecelakaan yang besar dikarenakan CV Cipta Mandiri selalu memperhatikan keselamatan para pekerjanya dengan melengkapi sarana dan prasarana untuk keselamatan para pekerja. Alat pelindung diri yang efektif serta alat yang aman saat digunakan mejadi suatu hal yang penting agar tidak tejadi kecelakaan pada saat bekerja.

b) Kondisi Fisik Lingkungan Ruang Kerja

Tabel 3. Klasifikasi Sarana dan Prasarana Alat Di Tempat Kerja CV Cipta Mandiri 


\begin{tabular}{|c|c|c|c|}
\hline No & $\begin{array}{l}\text { Jenis } \\
\text { kegiatan } \\
\text { di stasiun } \\
\text { kerja }\end{array}$ & Pekerjaan yang dilakukan & Kondisi lingkungan \\
\hline 1 & $\begin{array}{l}\text { Tempat } \\
\text { mesin } \\
\text { pembuta } \\
\mathrm{n} \text { bahan } \\
\text { mentah } \\
\text { triplek }\end{array}$ & $\begin{array}{l}\text { Menyangkut dari bahan mentah kayu } \\
\text { gelondongan menjadi lempengan } \\
\text { dengan menggunakan alat angkut lori } \\
\text { yang dimasukkan ke mesin pengelupas } \\
\text { kayu gelondongan. Kemudian } \\
\text { dimasukkan ke mesin giling untuk } \\
\text { menghasilkan lempengan kayu, dan } \\
\text { kemudian lempengan kayu dimasukkan } \\
\text { ke mesin pres agar menghasilkan bahan } \\
\text { yang sesuai. }\end{array}$ & $\begin{array}{l}\text { Suhu sekitar banyak } \\
\text { serpihan kayu dimana-mana, } \\
\text { pencahayaan, mesin kerja } \\
\text { bergerak memutar, tanpa } \\
\text { pagar pembatas, kebisingan, } \\
\text { dan pekerja kurang } \\
\text { menggunakan APD. }\end{array}$ \\
\hline 2 & $\begin{array}{l}\text { T e m p a t } \\
\text { m e s i n } \\
\text { g r i n d e r } \\
\text { (pengasah } \\
\text { pisau). }\end{array}$ & $\begin{array}{l}\text { Adanya bak penampungan air, yang } \\
\text { dilengkapi dengan bahan-bahan kimia } \\
\text { dan gerinda agar pisau tidak mudah } \\
\text { berkarat. }\end{array}$ & $\begin{array}{l}\text { Suhu lingkungan, bak } \\
\text { penampungan air kurang } \\
\text { memadahi, licin, } \\
\text { pencahayaan, dan tidak } \\
\text { adanya pagar pembatas, } \\
\text { pekerja jarang menggunakan } \\
\text { APD. }\end{array}$ \\
\hline 3 & $\begin{array}{l}\text { T e m p a t } \\
\text { penataan } \\
k \text { a y u } \\
\text { gelondong } \\
\text { an }\end{array}$ & $\begin{array}{l}\text { Menempatkan kayu gelondongan pada } \\
\text { tempat penataan kayu dengan tinggi } 1 \\
\mathrm{~m} \text {, dengan menggunakan mesin katrol } \\
\text { dan dikondisikan dalam keadaan rata. }\end{array}$ & $\begin{array}{l}\text { Suhu sekitar, } \\
\text { pencahayaannya, tempat } \\
\text { landasan kayu kurang } \\
\text { memadahi, kebisingan, tidak } \\
\text { adanya pagar pembatas, } \\
\text { pekerja jarang mengguna- } \\
\text { kan APD. }\end{array}$ \\
\hline 4 & $\begin{array}{l}\text { T u n g k u } \\
\text { bakar }\end{array}$ & $\begin{array}{l}\text { Membakar bahan sisaan dari kayu } \\
\text { yangtidak dipakai lagi, dan dimasukkan } \\
\text { ke dalam tungku pembakaran agar asap } \\
\text { tidak mencemari daerah sekitar. }\end{array}$ & $\begin{array}{l}\text { Suhu sekitar, pencahayaan, } \\
\text { tempat hasil akhir kayu yang } \\
\text { dibakar kurang memadahi, } \\
\text { adanya pagar pembatas, } \\
\text { pekerja sudah menggunakan } \\
\text { APD. }\end{array}$ \\
\hline
\end{tabular}

Tabel di atas menunjukkan bahwa setiap ruang kerja memiliki kondisi lingkungan yang berbeda. Hal ini bisa menunjukkan risiko kecelakaan kerja yang berbeda di setiap ruang kerja. Risiko kecelakaan terbesar terdapat di ruang mesin serta tungku pembakaran karena tidak adanya pagar pembatas serta suhu ruangan yang sangat tinggi sehingga karyawan memiliki resiko yang cukup besar terhadap terjadinya kecelakaan kerja.

\section{2) Komitmen Perusahaan}

Komitmen perusahaan sangat penting untuk melindungi keselamatan para pekerja. Ini menjadikan karyawan akan selalu merasa aman dan nyaman dalam bekerja apabila perusahaan mempunyai komitmen untuk melindungi keselamatan karyawan. Adanya komitmen dari perusahaan diharapkan mampu menciptakan produktifitas kerja yang baik.

Komitmen CV Cipta Mandiri dalam melindungi karyawan ditunjukkan dengan adanya fasilitas pendukung seperti perlengkapan P3K. Adanya P3K diharapkan dapat mencegah hal yang lebih buruk apabila terjadi kecelakaan pada saat bekerja. Pernyataan bahwa perusahaan memiliki perlengkapan $\mathrm{P} 3 \mathrm{~K}$ diungkapkan beberapa responden sebagai berikut : 
"sudah ada P3K diletakkan dikantor." (Responden A)

"ya ada didalam kantor." (Responden B)

"fasilitas P3K ada diletakkan didalam kantor." (Responden C)

Selain adanya fasilitas P3K, juga terdapat pengarahan sebelum karyawan melakukan pekerjaannya. Hal ini untuk mengingatkan karyawan serta upaya mencegah terjadinya kecelakaan pada saat bekerja. Pernyataan ini diungkapkan dalam wawancara berikut :

“...Kita beri pengarahan dulu sebelum bekerja." (Responden A)

"...ada pengarahan dari kepala kantor." (Responden B)

"Sebelum melakukan pekerjaan diberi pengarahan dulu untuk keselamatan waktu kerja..." (Responden C)

Komitmen lain perusahaan untuk menjamin keselamatan karyawannya maka setiap karyawan CV Cipta Mandiri diberikan asuransi kesehatan. Hal ini diungkapkan oleh kepala kantor sebagai berikut :

"semua karyawan disini mendapat asuransi dari kantor pusat apabila terjadi kecelakaan selama bekerja dan ditanggung perusahaan biayanya." (Responden A)

Hal yang sama juga diungkapkan oleh beberapa karyawan saat wawancara sebagai berikut :

"Kita dapat asuransi kesehatan semua." (Responden B)

"Ya, setiap karyawan mendapat asuransi." (Responden C)

Adanya komitmen dari perusahaan diharapkan mampu meningkatkan produktifitas kerja para karyawan agar mereka selalu aman dalam bekerja, dengan demikian perusahaan dapat menjalankan usahanya dengan mudah.

Tabel 4. Hasil Identifikasi Potensi Resiko Kecelakaan Kerja Di Tempat Produksi Bahan Mentah

\begin{tabular}{|c|c|c|c|c|}
\hline & & & \multicolumn{2}{|c|}{ Penyebab kecelakaan } \\
\hline Jenis kegiatan & $\begin{array}{l}\text { Potensi } \\
\text { bahaya }\end{array}$ & $\begin{array}{l}\text { Resiko } \\
\text { bahaya }\end{array}$ & Tindakan tidak aman & Kondisi tidak aman \\
\hline $\begin{array}{l}\text { T e m p a t } \\
\text { bahan mentah } \\
\text { atau kayu } \\
\text { gelondo-ngan }\end{array}$ & $\begin{array}{l}\text { Te t i m pa } \\
\text { k a y u } \\
\text { gelondo- } \\
\text { ngan }\end{array}$ & $\begin{array}{l}\text { Lecet, memar, } \\
\text { b e n g k a k, } \\
\text { patah tulang. }\end{array}$ & $\begin{array}{l}\text { Banyak bercanda, } \\
\text { kurangnya kosentrasi, } \\
\text { gegabah dalam } \\
\text { bekerja, tidak } \\
\text { menggunakan APD. }\end{array}$ & $\begin{array}{l}\text { Tempat tumpuan } \\
\mathrm{k} \text { a y u } \mathrm{t} \mathrm{i} \mathrm{d} \mathrm{a} \mathrm{k} \\
\text { memadahi, licin. }\end{array}$ \\
\hline & $\begin{array}{l}\text { Kejang otot, } \\
\text { t e r j a t u h, } \\
\text { terpeleset }\end{array}$ & $\begin{array}{l}\mathrm{K} \text { e } \mathrm{s} \text { e I e o } \\
\text { memar, patah } \\
\text { tulang }\end{array}$ & $\begin{array}{l}\text { Tidak kosentrasi, } \\
\text { melamun, bercanda }\end{array}$ & $\begin{array}{l}\text { Tempat tumpuan } \\
\text { k a y u t i d a k } \\
\text { memadahi, licin. }\end{array}$ \\
\hline & $\begin{array}{l}\text { Jatuh dari } \\
\text { ketinggian }\end{array}$ & $\begin{array}{l}\text { Patah tulang, } \\
\text { cacat, memar }\end{array}$ & $\begin{array}{l}\text { T e r b u r u - b u ru, } \\
\text { bercanda, melamun } \\
\text { dalam bekerja }\end{array}$ & $\begin{array}{l}\text { Lantai licin, } \\
\text { tumpuan kayu } \\
\text { sudah rapuh }\end{array}$ \\
\hline & Terjepit & $\begin{array}{l}\text { Luka lecet, } \\
\text { patah tulang, } \\
\text { bengkak }\end{array}$ & $\begin{array}{l}\text { Kurang kosentrasi, } \\
\text { terburu-buru, tidak } \\
\text { menggunakan APD }\end{array}$ & $\begin{array}{l}\text { Tempat tumpuan } \\
\text { kayu roboh }\end{array}$ \\
\hline
\end{tabular}


Tabel 5. Hasil Identifikasi Potensi Resiko Kecelakaan Kerja Di Ruang Mesin CV Cipta Mandiri

\begin{tabular}{|c|c|c|c|c|c|}
\hline & & & & \multicolumn{2}{|c|}{ Penyebab kecelakaan } \\
\hline No & $\begin{array}{c}\text { Jenis } \\
\text { kegiatan }\end{array}$ & $\begin{array}{l}\text { Potensi } \\
\text { bahaya }\end{array}$ & $\begin{array}{l}\text { Resiko } \\
\text { bahaya }\end{array}$ & $\begin{array}{c}\text { Tindakan tidak } \\
\text { aman }\end{array}$ & Kondisi tidak aman \\
\hline \multirow[t]{2}{*}{1} & 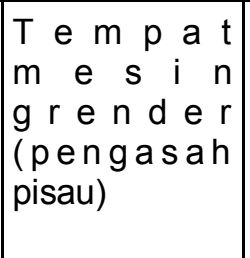 & 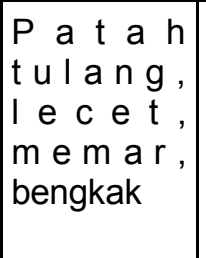 & $\begin{array}{l}\text { C a c a } t \\
\text { ke matian, } \\
\text { luka potong }\end{array}$ & $\begin{array}{l}\text { K u r a } n \text { g } n \text { y a } \\
\text { k o n s e } n \text { t } r \text { a s i, } \\
\text { bercanda, tergesa- } \\
\text { g e } s \text { a, t i d a k } \\
\text { mengguna-kan APD }\end{array}$ & $\begin{array}{l}\text { Ketajaman pisau } \\
\text { potong, tidak adanya } \\
\text { alat pengaman pada } \\
\text { pengasahan pisau } \\
\text { potong, kurangnya } \\
\text { APD. }\end{array}$ \\
\hline & & $\begin{array}{l}\text { Terpotong, } \\
\text { tergores }\end{array}$ & $\begin{array}{l}\text { L e c c e e t , } \\
\text { patah, luka } \\
\text { dalam }\end{array}$ & $\begin{array}{l}\text { Kurang kosentrasi, } \\
\text { bercanda, } \\
\text { mengguna-kan } \text { APD }\end{array}$ & $\begin{array}{l}\text { Tidak adanya alat } \\
\text { pengaman pisau } \\
\text { potong, tidak adanya } \\
\text { APD }\end{array}$ \\
\hline \multirow[t]{2}{*}{2} & $\begin{array}{lllll}\text { M } & \text { e } & \text { s } & \text { i } & n \\
\text { pengelupas } \\
k & \text { a } & \text { y } & \text { u } \\
\text { gelondongan } \\
\text { (spindle) }\end{array}$ & Terjepit & $\begin{array}{l}\text { Luka lecet, } \\
\text { p a t a h }, \\
\text { m en ge elu- } \\
\text { pas }\end{array}$ & $\begin{array}{l}\text { Bercanda, tidak } \\
\text { b erkosentras, } \\
\text { melamun }\end{array}$ & $\begin{array}{l}\text { Mesin bergerak tidak } \\
\text { sesuai dengan } \\
\text { instruksi kerja }\end{array}$ \\
\hline & & $\begin{array}{l}\text { Terke na } \\
p \text { i s a } u \\
\text { pengelupa } \\
s\end{array}$ & Patah, lecet & \begin{tabular}{|l} 
Bercanda, \\
kosentrasi,
\end{tabular} & $\begin{array}{l}\text { Tidak menyesuai-kan } \\
\text { instruksi kerja mesin }\end{array}$ \\
\hline \multirow[t]{2}{*}{3} & Mesin potong & 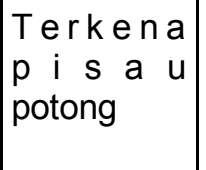 & $\mid \begin{array}{l}\mathrm{L} \text { e c e } \mathrm{t} \\
\text { patah, } \\
\text { tergores }\end{array}$ & $\begin{array}{l}\text { Banyak bercanda, } \\
\text { ngalamun, tidak } \\
\text { mengguna-kan APD }\end{array}$ & $\begin{array}{l}\text { Waktu penggunaan } \\
\text { mesin potong tidak } \\
\text { m em perhati-kan } \\
\text { instruksi kerja }\end{array}$ \\
\hline & & $\begin{array}{l}\text { Te rje pit } \\
p \text { i s a } \quad u \\
\text { potong }\end{array}$ & $\begin{array}{l}\mathrm{L} \text { e c e } \mathrm{t} \\
\text { tergores, } \\
\text { patah }\end{array}$ & $\begin{array}{l}\text { Tidak kosentrasi, } \\
\text { melamun }\end{array}$ & $\begin{array}{l}\text { Kurangnya disiplin } \\
\text { dalam bekerja, tidak } \\
\text { m em perhati - kan } \\
\text { instruksi kerja }\end{array}$ \\
\hline 4 & 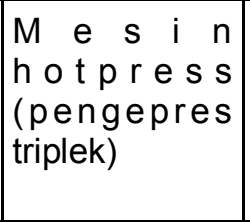 & $\begin{array}{l}\text { Kesetrum, } \\
\text { kebakaran, } \\
\text { keseleo }\end{array}$ & $\begin{array}{l}\text { Memar, luka } \\
\text { bakar, lecet }\end{array}$ & $\begin{array}{l}\text { K u r a n g n y a } \\
\text { berkosentari, } \\
\text { melamun, tidak } \\
\text { memperhati-kan } \\
\text { instruksi kerja }\end{array}$ & $\begin{array}{l}\text { Tidak terdapat } \\
\text { penutup mesin waktu } \\
\text { mesin bergerak, } \\
\text { adanya kabel yang } \\
\text { terkelupas } \\
\end{array}$ \\
\hline 5 & 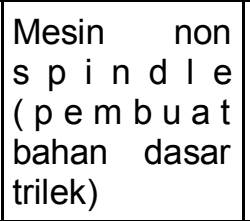 & $\begin{array}{l}\text { L e c e t } \\
\text { terkoyok, } \\
\text { memar, } \\
\text { kesetrum }\end{array}$ & $\begin{array}{l}\text { C a c a } \mathrm{t}, \\
\text { kematian, } \\
\text { kebakaran }\end{array}$ & $\begin{array}{l}\text { Kurang memperhati- } \\
\text { kan instruksi kerja, } \\
\text { kurang kosentrasi, } \\
\text { tergesa-gesa }\end{array}$ & $\begin{array}{l}\text { Lantai licin, tidak ada } \\
\text { tumpuan kaki, tidak } \\
\text { adanya penutup } \\
\text { mesin }\end{array}$ \\
\hline 6 & Tungku bakar & 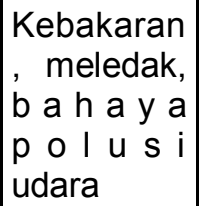 & $\begin{array}{l}\text { Luka bakar, } \\
\text { c a c a t } \\
\text { gangguan } \\
\text { pernafasan }\end{array}$ & $\begin{array}{l}\text { Adanya } \\
\text { kecerobahan dalam } \\
\text { bekerja, melamun, } \\
\text { tidak memerhati-kan } \\
\text { istruksi kerja }\end{array}$ & $\begin{array}{l}\text { Tidak adanya alat } \\
\text { pemadam kebakaran, } \\
\text { kurangnya lubang } \\
\text { asap. }\end{array}$ \\
\hline
\end{tabular}

3) Cara Pelaksanaan dan Pencegahan Kecelakaan Kerja

Selain ketersediaan sarana, prasarana, dan adanya komitmen perusahaan, juga diperlukan cara pelaksanaan pencegahan kecelakaan 
kerja. Pelaksanaan pencegahan kecelakaan kerja dapat mencegah terjadinya kecelakaan kerja lebih dini. Kepala kantor CV Cipta Mandiri menyatakan bahwa semua karyawan mendapat pelatihan dan penyuluhan, seperti yang diungkapkan dalam hasil wawancara berikut :

"Ya, semua karyawan sudah diberikan penyuluhan." (Responden A)

"...saya yang memberikan pelatihan memakai buku pedoman yang sudah ada." (Responden A)

Hal yang sama diungkapkan oleh karyawan bahwa mereka telah mendapat pelatihan. Peryataan ini disampaikan dalam hasil wawancara berikut :

“Langsung kepala kantor yang melatih..." (Responden B)

"pelatihan sudah pernah dilakukan, langsung kepala kantor tapi harapannya sering diadakan..." (Responden C)

Selain pelatihan karyawan juga mendapat penyuluhan seperti diungkapkan responden sebagai berikut :

"sudah pernah tapi tidak rutin penyuluhannya." (Responden B)

"ya sudah pernah diberikan penyuluhan tapi dari kepala kantor tapi kayaknya masih kurang..." (Responden C)

Cara pelaksanaan pencegahan yang lain yaitu adanya prosedur dalam pemakaian alat berbahaya. Menurut responden sudah ada prosedur tersebut dan sudah diterapkan seperti diungkapkan dalam hasil wawancara sebagai berikut :

“.. selama ini sudah diterapkan dengan cukup baik meski harus selalu diingatkan dulu." (Responden A) "diterapkan sesuai prosedurnya." (Responden B)

"selama ini diterapkan dengan baik..." (Responden C)

\section{b. Pembahasan}

\section{1) Sarana dan Prasarana Keselamatan dan Kesehatan Kerja}

Berdasarkan hasil penelitian maupun pengamatan menunjukkan bahwa sarana dan prasarana K3 CV Cipta Mandiri sudah cukup lengkap. Sarana yang tersedia mulai dari alat pelindung diri maupun sarana pendukung seperti kondisi lingkungan kerja. Ketersediaan sarana dan prasarana untuk mencegah terjadinya kecelakaan kerja sangat penting karena secara langsung melindungi para karyawan dari gangguan kerja. Hal ini bisa terlihat secara langsung bahwa selama ini belum pernah terjadi kecelakaan kerja yang serius karena sarana maupun prasarana yang selalu tersedia dengan baik.

Di CV Cipta Mandiri kondisi lingkungan kerja pada saat ini cukup baik meskipun masih ada kekurangannya seperti tidak adanya pembatas mesin, mupun lantai yang cukup licin. Kondisi lingkungan yang baik diharapkan mampu menciptakan suasana kerja yang aman dan nyaman. Disamping itu juga, masih terdapat petugas yang lalai mengunakan pelindung pada saat bekerja juga harus diperhatikan, karena alat pelindung menjadi salah satu alat pengaman utama dalam bekerja agar pekerja selamat selama 
menyelesaikan pekerjaannya. Suma'mur ${ }^{3}$ menyatakan bahwa kondisi lingkungan kerja seperti suhu ruang, penerangan dan penggunaan alat pelindung diri menjadi faktor penting seorang bekerja dalam menghasilkan pekerjaan yang berkualitas. Kondisi lingkungan dalam bekerja harus benarbenar diperhatikan agar karyawan dalam bekerja bisa maksimal.

Adanya sarana dan prasarana dapat melindungi keselamatan dan mencegah terjadinya kecelakaan dalam bekerja. Sesuai dengan penelitian yang dilakukan Sambudi ${ }^{4}$ bahwa salah satu cara untuk mengendalikan kecelakaan kerja dengan melengkapi sarana dan prasarana kerja serta adanya alat pelindung diri. Di CV Cipta Mandiri saat ini sarana dan prasarana sudah cukup baik sehingga diharapkan mampu mengendalikan keselamatan dan mencegah kecelakaan kerja. Sarana yang lengkap juga dapat membantu menjalankan sistem manajemen kesehatan dan kecelakaan kerja sehingga bisa meningkatkan produktivitas kerja. Penelitian yang dilakukan Mubarok $^{5}$ juga menunjukkan hasil yang sama bahwa minimnya kecelakaan kerja dapat meningkatkan produktivitas kerja pegawai.

Meskipun kelengkapan sarana dan parasarana sudah cukup baik. Akan tetapi tetap perlu ada perbaikan seperti kondisi lingkungan kerja harus lebih diperhatikan lagi agar para pekerja merasa nyaman dan aman dalam bekerja. Pekerja harus selalu diingatkan untuk selalu memakai alat pelindung agar terhindar dari bahaya pada saat bekerja, sehingga diharapkan pekerja mampu bekerja secara maksimal dan bisa menghasilkan produktivitas kerja yang tinggi.

\section{2) Komitmen Manajemen Perusahaan}

Komitmen manajemen perusahaan CV Cipta Mandiri sudah sangat baik. Hal ini terlihat jelas bahwa setiap pekerja memperoleh jaminan kesehatan atau asuransi. Selain itu juga tersedia fasilitas pendukung seperti adanya kelengkapan P3K di dalam kantor. Adanya komitmen perusahaan tersebut dapat menjadikan pekerja bekerja dengan nyaman karena mereka tidak akan mengkhawatirkan apabila terjadi kecelakaan kerja. Notoadmodjo ${ }^{2}$ menyatakan bahwa komitmen manajemen dalam perusahaan mempunyai peran penting dalam menjalankan cara pengendalian K3. Hal ini juga dilakukan dilakukan oleh perusahaan CV Cipta Mandiri dengan membuat program asuransi bagi pekerja. Selain program itu juga terdapat lembaga khusus untuk menangani K3.

Komitmen yang baik dari perusahaan tersebut di diharapkan mampu meningkatkan produktivitas kerja para pekerja. Seperti hasil penelitian yang dilakukan oleh Mubarok ${ }^{5}$. Tersedianya lembaga yang menangani K3 dapat menjalankan sistem keselamatan dan kecelakaan kerja karena pekerja akan selalu terlindungi setiap kali bekerja. Keberadaan P2K3 sebagai lembaga yang khusus menangani sistem K3 di perusahaan tersebut juga dapat menurunkan biaya akibat kecelakaan kerja. Hasil yang sama juga didapat dari penelitian Nurhayati ${ }^{1}$ bahwa adanya program K3 mampu menurunkan biaya akibat kecelakaan kerja sehingga perusahaan bisa lebih efektif.

Komitmen tersebut harus selalu dijalankan dengan baik agar ke depan perusahaan bisa lebih produktif dan pekerja merasa aman dalam melakukan pekerjaan. Karena komitmen perusahaan sangat penting dalam menjalankan sebuah sistem manajemen K3 agar berjalan dengan baik. Adanya komitmen dalam perusahaan juga mampu meningkatkan kepercayaan pekerja terhadap perushaan sehingga dapat berdampak pada hubungan yang baik antara pekerja dengan perusahaan. Secara 
keseluruhan bahwa manajemen CV Cipta Mandiri memiliki komitmen yang bagus untuk menjamin keselamatan dan kesehatan kerja para pekerja disana. Meskipun masih ada beberapa hal yang memang perlu diperbaiki secara terus menerus agar mutu perusahaan menjadi lebih baik.

\section{2) Cara Pelaksanaan Pencegahan}

Perusahaan CV Cipta Mandiri melaksanakan beberapa program lain untuk mencegah terjadinya kecelakaan kerja. program tersebut antara lain pelatihan, penyuluhan, pemeriksaan kesehatan rutin, serta pengarahan sebelum pekerja melakukan pekerjaannya. Program yang dibuat oleh perusahaan dapat mencegah terjadinya kecelakaan kerja pada CV Cipta Mandiri karena selama ini program tersebut sangat efektif dan berjalan dengan baik.

Program pelaksanaan pencegahan sangat penting untuk menjalankan suatu manajemen K3. Agar berjalan dengan baik maka perlu program yang dilaksanakan secara rutin oleh perusahaan. Saat ini perusahaan CV Cipta Mandiri belum melakukan program pencegahan secara kontinu karena program yang dilakukan hanya sekali saja kecuali pengarahan sebelum bekerja. Suma'mur ${ }^{3}$ menyatakan bahwa pelaksanaan program pencegahan kecelakaan kerja dapat menurunkan biaya yang dikeluarkan perusahaan. Begitu juga dengan yang dilakukan oleh CV Cipta Mandiri, program-program pencegahan kecelakaan diharapkan mampu menurunkan biaya. Penelitian yang sama juga dihasilkan oleh Nurhayati ${ }^{1}$ bahwa adanya program keselamatan dan kecelakaan kerja dapat menurunkan biaya akibat kecelakaan kerja.

Namun, perlu ada perbaikan program pelaksanaan pencegahan kecelakaan seperti adanya poster-poster K3 sehingga penerapan sistem manajemen $\mathrm{K} 3$ bisa berjalan lebih baik lagi. Hal ini dikarenakan penerapan program K3 di CV Cipta Mandiri sudah berjalan dengan baik. Untuk itu perlu upaya untuk terus mempertahankan agar perusahaan bisa produktif.

\section{SIMPULAN DAN SARAN}

a. Simpulan

1) Sarana dan prasarana untuk menunjang sistem manajemen $K 3$ sudah lengkap.

2) Perusahaan CV Cipta Mandiri memiliki komitmen untuk menerapkan manajemen keselamatan dan kesehatan kerja dengan memberikan asuransi kesehatan bagi setiap pekerja.

3) CV Cipta Mandiri sudah melaksanakan program pengendalian dan pencegahan terjadinya kecelakaan kerja dengan baik berupa pelatihan dan penyuluhan bagi para pekerja meskipun perlu dilakukan secara rutin.

c. Saran

1) Perusahaan harus memasang poster-poster tentang $K 3$ sebagai petunjuk tambahan bagi pekerja untuk selalu waspada dalam bekerja.

2) Melengkapi sarana prasarana seperti alat pelindung diri yang masih terbatas jumlahnya dan alat pemadam kebakaran harus selalu dipelihara agar berfungsi dengan baik.

3) Perusahaan membuat rencana program pelatihan dan penyuluhan agar program ini bisa terlaksana secara rutin. 


\section{DAFTAR PUSTAKA}

1. Nurhayati, Evaluasi Program Keselamatan dan Kesehatan Kerja Untuk Menurunkan Biaya Akibat Kecelakaan (Studi Kasus Pada PT Madu Baru Yogyakarta), Skripsi, Universitas Ahmad Dahlan, Yogyakarta. 2006

2. Notoatmodjo, S., Pendidikan dan Perilaku kesehatan, PT Rineka Cipta, Jakarta. 2007

3. Suma'mur P.K., Higiene Perusahaan dan Keselamatan Kerja, PT Gunung Agung, Jakarta. 1988

4. Sambudi, D., Pelaksanaan Keselamatan dan Kesehatan Kerja di Rumah Sakit Umum Daerah Bangking, Skripsi, Universitas Gajah Mada, Yogyakarta. 2007

5. Mubarok, Minimasi Kecelakaan Akibat Kerja dengan Penetapan Ergonomi untuk Meningkatkan Produktivitas. 2005 